\title{
Enhancing Student Achievement: The Importance of Second Level Educational Services in First Nation Schools in One Tribal Council in Saskatchewan
}

\author{
Larry Steeves \\ University of Regina \\ Sheila Carr-Stewart \\ University of Saskatchewan \\ Jim Marshall \\ University of Regina
}

\begin{abstract}
The primary purpose of this paper is an exploration of issues related to the provision of second level (central office) services available to schools within the Yorkton Tribal Council (YTC), a First Nations educational authority located in southeastern Saskatchewan. Research results supported the role of second level services in improving student learning and identified a shortfall in second level funding for the Yorkton Tribal Council. Key stakeholder focus groups from within the Yorkton Tribal Council agreed with these conclusions and identified a number of additional issues such as relevant curriculum, instruction, teacher recruitment and retention, and improved leadership and governance.
\end{abstract}

Keywords: second level services; governance; student achievement; First Nations educational authority; Yorkton Tribal Council 


\section{Enhancing Student Achievement: The Importance of Second Level Educational Services in First Nation Schools in One Tribal Council in Saskatchewan}

\section{The Context for the Study}

Until recently, a broad consensus of research suggested that schools had little impact on student learning. Coleman's research conducted in 1966 profoundly shaped North American attitudes to the value of schools as a means of addressing socio-economic inequality. Recently research has challenged such conclusions. Grissmer and Flanagan (2006) suggested that both the level of expenditures per pupil, as well as its allocation, affected student achievement levels, particularly in American states with higher levels of minority and less advantaged students. Other research suggested similar results with respect to First Nations education. John Richards (2008), whose research focussed within the province of British Columbia, argued that the quality of schools and individual educational experiences make a positive difference regarding student achievement. Richards' work further indicated that increased attention to primary and secondary education for Aboriginal youth should perhaps be the most important priority from a policy and financial perspective, for provincial and federal governments in Canada.

Calvin Helin (2008) documented the devastation visited on First Nation populations, resulting in a dependency framework that continues to wreak destruction on some communities. He suggested improved educational outcomes as one of the critical priorities for a more successful educational future for Aboriginal students. A study completed for Yorkton Tribal Council (2009) suggested that improved student support services can produce improved student learning: "There is a rich body of research literature that demonstrates the effectiveness of student support services, including their contribution to the personal and academic success of students” (p. 45).

The research, which formed the basis of this paper, was designed to clarify understanding of the most effective means of achieving improved educational outcomes for Aboriginal students and the role of second level educational services provided to students attending First Nations schools within one Tribal Council. Our research investigated the delivery of second level (central office) services, including director of education, curriculum, student services, and technology support, within a Saskatchewan First Nations jurisdiction, the Yorkton Tribal Council (YTC). Issues related to second level services, including the relative level of funding available for such services and the perspectives of local Yorkton Tribal Council stakeholder groups, were central to the research. Research results both supported the need for enhanced second level funding, as well as raising a number of other issues that merit consideration.

\section{The Research Journey}

The initial impetus for this research relates to an innocuous event that occurred in Yorkton, Saskatchewan several years ago. One of the researchers for this study had invited the Director of Education for the Yorkton Tribal Council to address his graduate seminar in organizational theory. The Director of Education arrived at the Saturday class and though he had been ill for several days, still managed to deliver a powerful message to the students regarding First Nations education. When questioned by the researcher regarding the danger of stress and over work, the Director commented that, given the resources available to him and his organization, there were few available options. The paucity of resources to support second level services-whether in curriculum, student services, or other areas-meant that, if the Director and his staff were to 
attempt to meet the second level service needs of students, teachers, and schools in the Yorkton Tribal Council, they would be forced to carry a heavy load.

Thus was born the Yorkton Tribal Council research initiative-Improving Student Learning: A Study of the Contribution of Enhanced Second Level Services Within the Yorkton Tribal Council in Relation to the Saskatchewan Pre-K to Grade12 Educational System. This research included a consideration of jurisdictional issues, of research related to First Nations and Métis student achievement, of the role of central office services in supporting student achievement, an analysis of Yorkton Tribal Council second level, or central office, supports as compared to provincial comparators, and, at the request of the Director of Education, a review of successful central office support models within provincial systems of education. The research results support the comments made by the Director of Education on that Saturday in Yorkton. Subsequent research not only supported the role of second level services but also illustrated the limited nature of resources available for these services, at least within the Yorkton Tribal Council, and suggested other initiatives in order to support student learning.

Following the conversation described above, I contacted other academic colleagues regarding the need for research concerning the availability of First Nations second level educational services. The response was overwhelming; the principal investigators were shortly joined by other researchers interested in exploring the topic and, hopefully, making a constructive contribution to students within Yorkton Tribal Council. Similarly, financial support for the research was received from the Yorkton Tribal Council, the Saskatchewan Instructional Development and Research Unit, Faculty of Education, University of Regina, the Saskatchewan Ministry of Education, and Indian and Northern Affairs Canada. The funding supported travel by researchers and community members, payment to graduate students involved in the research, and printing and mailing costs.

The funding for researchers working on this project resulted in six major pieces of work. These included a review of the history of First Nations educational governance, a consideration of issues related to Aboriginal students' achievement, the value of second level student services, an assessment of financial resources available to the Yorkton Tribal Council in relation to both second level services in one provincial jurisdiction, and, within Saskatchewan educational jurisdiction. The original objective of the study included conducting two focus groups with teachers and school administrators. Time pressures forced the postponement of this aspect of the original study to a Phase 2 component of the research.

After a 6 month lapse, Phase 2 of the research broadened the original research to include a series of focus groups conducted with key stakeholders within the Yorkton Tribal Council. Involving a broader range of community groups provided a richer set of local perspectives regarding the need for improved second level services. It also provided an opportunity to assess the findings of the earlier studies from a local perspective. This served to enrich and broaden the earlier findings for improved second level services, highlighting the fact that funding and current service levels provided in First Nations schools are lower than similar services provided in provincial jurisdictions, and that funding and other critical issues must be addressed if the academic achievement of First Nations students in Yorkton Tribal Council is to improve.

\section{The Yorkton Tribal Council: A Brief Description}

Some sense of the Yorkton Tribal Council is necessary to appreciate the discussion related to its second level services. The Yorkton Tribal Council covers a large geographical area within 
southeastern Saskatchewan, representing five First Nations, Cote First Nation, Kahkewistahaw, Keeseekoose, Ocean Man, and Sakimay First Nation, with a total on-reserve population of 1915 (Don Pinay, personal communication, 2009).

\section{Educational Services}

Educational services are provided to schools located on the above reserves with a total student enrolment of 1088 students and also to schools located at White Bear, Cowessess, and Ochapowace First Nations (these three nations are not members of YTC) with an additional 488 students. Services provided for the Pre-Kindergarten to Grade 12 by the Director of Education, and staff include

- supervisory services in program and instruction activities of member First Nation Schools;

- all professional development activities are coordinated through the In-School Department; and

- Education Psychometrics and Speech Pathology services for the member schools are contracted through the Yorkton Tribal Council offices.

\section{The Research}

As stated above, the research was conducted in two phases; Phase 1 related to second level supports from a broad perspective, both nationally and internationally, and Phase 2 included discussions with Elders, parents, students, teachers, school-based administrators, and elected officials.

\section{Phase 1}

Phase 1 focussed on the challenges and opportunities faced by providers of First Nations education and the need for effective second level services. A brief history of the educational governance outlined the troubled history of First Nations governance:

Over the last century, provincial initiatives-including education departments, governance structures, legal structures, and educational initiatives-have established a quality education system for Canadian children; a governance and administrative structure which supports local control and parental involvement is no less required and needed at the First Nations level. (Yorkton Tribal Council, 2009, p. 17)

Research on the relationship between Aboriginal children and student achievement indicated that within Saskatchewan completion rates of Aboriginal and Northern students have been consistently lower than other student cohorts. Furthermore, research indicated the need for a broad perspective when considering the means by which Aboriginal student achievement can be improved:

The message here is simple-student achievement must be viewed within a broader context. Attempts to focus narrowly on the educational issues outlined in this study will, in themselves, prove unsuccessful. While positive changes are occurring, attention to larger social, economic, and cultural issues is critical if student learning and achievement are to meaningfully improve. (Yorkton Tribal Council, 2009, p. 21)

Based on a review of literature, the Yorkton Tribal Council (2009) identified the following conceptual framework regarding factors that influence Aboriginal student achievement 
and, by extension, the need for effective second level services. These conclusions were based upon a review of the literature that focussed, in part, on the following characteristics of exemplar Aboriginal schools in Canada:

- $\quad$ strong leadership and governance structures;

- language and cultural programs;

- teachers, instruction, and curriculum;

- effective schools;

- $\quad$ community and parental influences;

- $\quad$ student characteristics;

- assessment linked to instruction and planning; and

- appropriate levels of funding. (p. 22)

The role of the school system in supporting teachers and school is an important aspect of improving student learning. The Yorkton Tribal Council (2009) study suggested that improved student support services can produce improved student learning, indicating that "there is a rich body of research literature that demonstrates the effectiveness of student support services, including their contribution to the personal and academic success of students” (p. 45).

The Yorkton Tribal Council (2009) study's conclusions regarding the need for solid central support services were echoed by a number of other researchers who argued that effective school system support is required for improved student achievement. For example, Fullan (2003) stated that tri-level reform was necessary for improved educational outcomes. He indicated that studies of effective schools often occur in isolation from other factors, suggesting that "we need dramatically more intensive interaction within schools, across schools within districts, across districts, and between districts and the state" (Fullan, 2003, pp. 39- 40). He further suggested that "you cannot have transformation by going it alone.... Dramatic increases in these types of interactions are required for transformation. Right now, schools and schools systems are decidedly not like this_structurally, normatively, culturally" (Fullan, 2003, pp. 39- 40). Fullan (2004) also considered a number of studies that investigated the means by which low performing schools closed the gap between themselves and high performing schools. Citing a study by Togneri and Anderson (2003), Fullan outlined six strategies for improvement that these school systems utilized: High performing schools

- $\quad$ publicly acknowledged poor performance and sought solutions (building the will for reform);

- focussed intensively on improving instruction and achievement;

- $\quad$ built a system-wide framework and infrastructure to support instruction;

- redefined and redistributed leadership at all levels of the district;

- enhanced professional development activities; and

- $\quad$ recognized that there were no quick fixes. (p. 2)

Since the original impetus for the study was to explore the issue of funding for second level services, the Yorkton Tribal Council (2009) study considered the relationship between 
second level funding within the provincial system and within Yorkton Tribal Council. Research results identified a consistent pattern-funding for second level services in Yorkton Tribal Council was lower than within the provincial system. Among the concluding comments related to this analysis, the researchers indicated that:

All of this analysis suggests that...the program budget for second level services within the schools operated by the members of the Yorkton Tribal Council was inadequate to provide service levels which would be similar to similar sized divisions operated within the Saskatchewan school system. (Yorkton Tribal Council, 2009, p. 67)

The message seemed clear; second levels services are funded at a lower level than provincial schools. Since the Yorkton Tribal Council (2009) study also demonstrated the importance of second level services, the lack of funding to support these services is problematic.

\section{Phase 2}

Given the time break, our research team opted to develop the focus group aspect of the research in a Phase 2 component. The research continued into second level services using focus group feedback from a wide group of stakeholders. This broader group included Elders, parents, students, teachers, school based administrators, and elected officials. These elected officials formed the Educational Commission for the Yorkton Tribal Council, which included one representative from each of the affiliated First Nations communities.

The Phase 2 research utilized a qualitative design, incorporating a mixed method approach of Indigenous methodology and grounded theory analysis. Kovach (2009, 2010) proposed an Indigenous epistemological orientation and recognized the need for a decolonizing lens in First Nations research. Kovach (2010) further suggested these frameworks should "shift the power of the researcher in controlling the research process and outcome" (p. 82), and allow for greater participant voice. With respect to First Nations research, Kovach acknowledged that knowledge is transferred through oral history and story, and suggested that a research method congruent with an Indigenous epistemology is the conversational method. It utilizes open-ended, semi-structured interview questions to gather data where the participant and researcher co-create knowledge. To make meaning of the data gathered in Phase 2 of the study, grounded theory and thematic analysis were utilized.

Following research ethics approval, the process of gathering focus group feedback commenced. These sessions occurred during the late winter and spring of 2009. The three researchers involved in conducting the focus groups sessions included both First Nations and non First Nations individuals. The focus groups were essentially asked to provide feedback regarding student achievement and the need and nature of second level educational supports from the Yorkton Tribal Council. Key research questions directed to the focus groups included a focus upon the things that the Yorkton Tribal Council could do to ensure a successful learning experience, factors that might prevent this from occurring, and the type of resources that would be required to address these issues. Consistent with Kovach's (2009, 2010) methodology, the process was open-ended and provided ample opportunity for focus group participants to shape their responses in ways they considered most beneficial. This more open approach to the focus group process produced interesting results. Feedback was instructive in ways that the research team did not originally anticipate. It not only provided valuable information regarding the nature of second level services within the Yorkton Tribal Council, but it also suggested a high degree of consistency and aligned closely with the research results from Phase 1 of the study. 
In effect, the focus groups provided a valuable validity check of the research results identified within the first phase of the study. The more detailed discussion that follows will provide an opportunity to further explore this relationship.

Appropriate levels of funding. An overwhelming consensus regarding the shortage of funding existed within the feedback of all focus groups. Members of the Educational Commission commented that the Yorkton Tribal Council was doing the best that they could in the situation, but that the funding was not there for second level positions. School administrators not only discussed the shortage of funding but also expressed frustration with both the slowness and conditionality of funding from Indian and Northern Affairs Canada. They also suggested that additional funding from other agencies such as Health Canada would be beneficial. The comments regarding funding from Health Canada were echoed in the feedback from the parent focus group. Parents also discussed the need for more teacher assistants, improved staff training, and enhanced after school programming.

Elders also expressed frustration with the level of funding, indicating that First Nations populations are growing but the funding was the same as it was in the 1980s. This frustration was not directed solely at Indian and Northern Affairs Canada; it was suggested that funding should also be provided by provincial authorities. One Elder commented that it was not only the provincial system that had community schools, but also First Nations have community school needs, yet receive no funding from the province.

Teacher comments focussed upon the need for funding to support children. They stated that they could use supports full time. One teacher commented that it came down to money but kids end up falling through the cracks. It was further suggested that what was saved in schools is paid for later in social assistance, hospitals, and other services.

The need for improved funding manifested itself in other ways. While students did not directly focus on funding, they discussed the need for improved school infrastructure, including issues such as poorly maintained portable classrooms. They also expressed concern about shortages of classroom and laboratory supplies and equipment. Finally they suggested that actions to ensure a more stable, qualified, and competent teaching force were necessary.

The relationship to the previous research findings in Phase 1 of the study seems clear. Key stakeholder groups in Yorkton Tribal Council believe that they receive inadequate educational funding-both at the school and Tribal Council level. While research findings indicated that second level services in Yorkton Tribal Council are funded at a lower level than the provincial system, it is difficult to draw similar conclusions regarding overall federal funding for First Nations schools in Saskatchewan. While research by Fulford, Moore Daigle, Stevenson, Tolley, and Wade (2007) and Bell et al. (2004) regarding exemplar schools across Canada suggested that this appears to be the case, it is difficult to make a solid research-based claim in Saskatchewan. However, whether justified or not, there is no question that stakeholders within the Yorkton Tribal Council believe that they are receiving inadequate funding, and funding that is less than within the provincial system.

Second level support staff. The feelings of frustration regarding funding shortages translated quickly into discussions regarding the need for improved second level service support. All focus groups indicated the need for enhanced second level services. Members of the Educational Commission stated that while the Yorkton Tribal Council had basic services such as speech pathologists, psychologists, and a Director of Education, these services required 
additional support. They commented that more human power was necessary. For example, one member of the Commission commented that they needed three more Don Pinays (Don Pinay is the current Director of Education for Yorkton Tribal Council). Commission members did not limit their comments to existing staff positions. They also expressed the need for social workers and qualified career and guidance counsellors.

These comments were echoed by school-based administrators who outlined the need for occupational therapists, a special education consultant, and mental health therapists. Administrators also expanded on the need for the enhancement of existing services. They reinforced the comments of the Educational Commission regarding the need for more curriculum support time, as well as more speech pathologist and psychologist services. School administrators indicated the need for more specialized services generally, commenting specifically on behaviour therapists and teachers with special education backgrounds. Teachers expressed similar sentiments, outlining the need for the enhancement of existing services, for the addition of an occupational therapist, for more special education and counselling support, as well as improved curriculum support, in particular a language arts consultant.

Reflecting their more local perspective, students discussed the need for improved substitute teachers, more teachers to avoid split grades, and better technology support. Parents shared a similar perspective, commenting on the need for more teacher assistants, as well as the type of support services described by other focus groups. Elders commented only briefly on this issue, but shared similar perspectives regarding the need for more and better trained support staff.

These comments might be expected, given the findings regarding lower levels of second level funding, as compared to the provincial system from Phase 1 of the study. The fact that the Yorkton Tribal Council receives lower levels of second level funding support logically translates into the consistent focus group feedback regarding the need for improved support services. It would appear that anecdotal feedback from the Yorkton Tribal Council would support the results of the financial analysis previously conducted.

Community and parental influences. The literature review conducted in the earlier phase of the study revealed the importance of effective community and parent relationships. The focus group feedback which reinforced this conclusion consistently stated the need for more effective community and parent support. Members of the Educational Commission talked about the need to connect the family with the school, suggesting that a definite improvement occurs, not only for students but also for parental self esteem, when this occurs.

School administrators concurred with these statements, suggesting that ineffective parenting is the root of the problem. One individual commented that parents need to be parents and not leave everything up to the school. However, administrators also referred to the importance of parental support and the need to work as a team to assist students. Teachers shared similar perspectives, as did students.

Parents commented that parents need to "step up,” suggesting the need for parenting classes to assist parents in some very troubled situations. They also discussed the need to build trust so that parents could use their voice within the school setting. Elders made similar statements, commenting both on poor parenting practices and the negative impact of residential school experiences on families. 
Language and cultural programs. A substantial body of research (Demmert \& Towner, 2003) identified in Phase 1 of the study supports the inclusion of language and cultural programming in First Nations schools. Focus groups' results consistently supported these research conclusions. Members of the Educational Commission commented that cultural implementation was important, referring to recent work by the Office of the Treaty Commissioner regarding awareness of treaties, both within provincial and First Nations classrooms. They also emphasized the need to involve Elders in the school to assist teachers with cultural awareness, as well as to assist with student and family support. Commission members further talked about the need to connect Indigenous knowledge, history, language, and culture, using Elders and the community to assist with this process. They indicated that the Yorkton Tribal Council could assist with this process by coordinating programming and by using the school community to provide local direction.

These views were generally shared by every focus group, and each group also emphasized the need to focus on language programming. For example, Elders commented that many people don't understand things like smudges. Elders also mentioned the challenges facing White teachers who know little of First Nations culture and language and the need for cross cultural education. Finally Elders spoke to the importance of working together with different cultures. One Elder suggested that, despite previous treatment and abuse, First Nations people need to accept what can’t be changed and move forward with a positive attitude.

Instruction and curriculum. In addition to the need for enhanced language and cultural programming, participant comments regarding instruction and curriculum outlined the need for a broader and more effective school programs. In addition to improved support for existing programs such as science, math, and extra-curricular activities, more programming in areas such as pre-school language development, anti-bullying, literacy programs, and libraries was identified. The area of extra-curricular activities was mentioned by students, parents, teachers, administrators, and Commission members. A typical comment was provided by a Commission member who suggested a need to prioritize physical education, hockey, basketball, and a healthy lifestyle, with a focus on the physical, mental, spiritual, and emotional elements.

Students discussed the need for more "hands on" instruction in science and computers, for better equipment and resource materials, and for more choice in programming in sports and shop classes. Teachers also referred to the need for improved equipment and maintenance, commenting specifically about issues such as the need for better technology support. They also discussed the need for a 5-year curriculum plan that would identify priorities which would be consistently pursued, rather than frequently changing curriculum programs. Teachers also emphasized the importance of in-service and training related to new curricula. One teacher indicated that Yorkton Tribal Council does provide support when new programs are implemented.

Almost all groups referred to the need for enhanced support programs. Parents commented that students at different levels need help, while an Elder indicated that many Grade 12 graduates couldn't read or write. This Elder referred to special programs outside the community, which were utilized when her daughter did not receive this needed type of support within her own community.

Teachers and teacher retention. In addition to focus group feedback regarding second level support, a wealth of comments with respect to teaching, curriculum, and instruction 
occurred. Much of this feedback has already been described; however, a number of additional comments, some of which were unforeseen, were also provided.

Perhaps the greatest amount of feedback regarding teachers was provided by students. They were clear regarding their expectations from the Yorkton Tribal Council and their home community. They wanted teachers who were well qualified, with experience, and the ability to make the subject content interesting. They commented that out of province teachers were often quiet and "not as good as they could be" (Steeves, interview notes, June 10, 2009). In response to a question concerning the need for Aboriginal teachers, students were clear that competence was more important than ethnicity.

Other comments, in particular from school administrators and teachers, related to the need for improved teacher retention. Administrators discussed the problem of staff turnover, indicating that teachers often come for 1 or 2 years and then leave. One administrator stated that only once did all teachers stay from one year to the next. With respect to the high turnover rate, reference was made to the issues surrounding teacher stability; one example was the problem of in-servicing teachers who then leave. Discussion as to the causes of this turnover included financial issues such as teachers leaving for more money elsewhere. Elders also suggested that parents did not go to the school to thank teachers, indicating that teachers experience much negativity and need to be supported. Teachers also addressed this issue, discussing the need to pay substitute teachers better in order to attract well-qualified, competent people.

Administrators commented regarding the need for greater security and protection. Teachers also discussed this issue, referencing the impact of local politics and indicating that if the elected representative does not like the teacher, then that person is not re-hired. Teachers talked about the need for longer contracts in First Nations schools as a means of reducing staff turnover. One individual referred to the relationship between family and employment, suggesting that native teachers have left the community because of local dynamics such as politics and families. Teachers suggested that to get the best people, you have to make the job attractive.

Leadership and governance. Leadership and governance were identified by Fulford et al. (2007) and Bell et al. (2004) as critical factors in exemplar Aboriginal schools in Canada. A related study by Maguire (2003) considered consistently improving Alberta school districts and found that their leadership and governance structures contributed to their overall effectiveness. Battiste and McLean (2005) emphasized the importance of First Nations control over education and the prospect for gradual improvement as capacity grows. However, within local control, challenges remain; Smith, Bear, Corrigan, and Quinn (2008), in a report for the 2008 Quebec Cree School Board Educational Review, identified serious management concerns related to the operation of the educational authority. In the Yorkton Tribal Council (2009) study, a discussion related to leadership and governance concluded with the following comment:

Clearly, local educational control will not necessarily address all the problems within the administration of First Nations school systems. However, careful attention to the types of practices outlined above will move First Nations schools and central jurisdictions in the correct direction. A failure to ensure that strong leadership and governance is in place will make it very difficult to tackle the types of reforms necessary to enhance student achievement. (p. 24)

Feedback from Yorkton Tribal Council focus participants echoed these conclusions. While participants realized their difficulties associated with the lack of local control over 
educational affairs, concerns were expressed regarding the issue of leadership and governance. Elders discussed the need for forums to articulate more clearly the vision for education. Elders and teachers talked of the need to educate their elected board members regarding the school issues, policies, and procedures. Administrators mentioned the need for interagency supports within individual Bands to work together more effectively.

Elders, teachers, and school administrators all referred to the debilitating role of local politics in the operation of the school. Elders suggested that politics are "poisonous", that leaders do not say anything because of the need for electoral support in the community. They proposed a larger role for Elders and indicated that people needed to take responsibility and help themselves. Teachers discussed the pernicious relationship between family politics and the school. These relationships meant that merit was not always the basis for teacher retention. Teachers also suggested that family issues cause students to attend off-reserve town schools.

School administrators talked of the need to separate education from Band office politics. They suggested elected board members have a specific mandate and responsibility for education. Teachers also raised this issue, suggesting that Band leaders don't always understand what is needed and are not always available to help address difficult issues. They indicated that more centralized boards, responsible for education, would take power away from each Band and family issues would not be as influential.

Assessment linked to instruction and planning. The Yorkton Tribal Council (2009) study referred in its findings to the importance of assessment linked to instruction and planning. It is noteworthy that no focus group feedback was provided regarding this topic. Participants did not identify this as a second level service that could be provided by the Yorkton Tribal Council. Whether there were simply more pressing priorities, or whether this typically becomes a priority when overall management reaches the point that more effective data and student achievement information is required for planning and decision making is an interesting question.

It is interesting to note that, subsequent to the focus group process, Treaty 4 has initiated a major initiative related to the use of student achievement data to improve school-based decision making (Don Pinay, personal communication, June 25, 2009). The Yorkton Tribal Council has been heavily involved in this initiative, helping to achieve federal funding to support it, as well as actively participating in the overall implementation of the program. This would suggest that senior decision makers see the area of assessment is an important priority. It may also be that, if the focus group were conducted now, participants would pay greater attention this topic. Notwithstanding these statements, it is instructive to note that the focus groups did not raise assessment as an important topic related to the provision of improved second level services by Yorkton Tribal Council.

\section{Enhancing Student Success and Second Level Services: A Concluding Comment}

From the inception of this study, researchers were motivated by a desire to make a positive contribution towards First Nations education. One colleague commented that she was tired of writing articles that received little attention beyond the academic community. She saw her participation in this venture as an opportunity for service. Based upon feedback from Don Pinay, the Director of Education for Yorkton Tribal Council, it appears that she has been successful; he has indicated that the study had a positive impact in a variety of settings. For example, a Yorkton Tribal Council principal recently commented that second level support services have improved dramatically. When questioned, Don Pinay commented that the results of the study were 
instrumental in persuading a variety of stakeholders to consider the need for improved second level services (Don Pinay, personal communication, June 25, 2009).

Researchers were also motivated by a desire to determine whether the perceptions regarding inadequate second level services were accurate. Based upon the research results, it appears that the perceptions were correct. However, other unanswered questions remain-for example, how does the level of funding for First Nations students compare to provincial systems? The research cited here, as well as wide spread perceptions in First Nation communities, would suggest that educational funding for First Nations funding is lower than provincial systems. However, other research does not support this conclusion. For example, Richards and Scott (2009) concluded that funding was roughly comparable between the two systems. More research is required if this controversial topic is to be clarified.

The research reported here has also raised other questions. One excellent example is the issue of leadership and governance raised within both the literature review related to student academic achievement in First Nations communities and the subsequent focus groups in the Yorkton Tribal Council. Can First Nations education systems achieve desired outcomes for their students until this important issue is meaningfully addressed?

Similar questions arise with respect to the issue of teacher recruitment and retention. Focus group feedback substantiated what is commonly heard-that systematic attention to this issue is required for meaningful progress in First Nations student success. Can schools hope to be successful if a large percentage of the teaching population changes on a regular basis?

In summary, it appears that the study has not only been helpful in effecting positive change, but has also helped to stimulate other key research questions for future research. It is hoped that on-going research results in second level educational service enhancement will produce program improvements that will assist First Nations students in reaching their full educational potential. A failure to ensure that First Nations children are not supported in this critical goal will dramatically diminish their future prospects, with consequences for all Canadians. 


\section{References}

Battiste, M., \& McLean, S. (2005). State of First Nations learning. Paper presented at the Canadian Council on Learning Ottawa, Ontario.

Bell, D., Anderson, K., Fortin, T., Ottoman, J., Rose, S., Simard, L., \& Spencer, K. (2004). Sharing our success: Ten case studies in Aboriginal schooling. Kelowna, BC: Society for the Advancement of Excellence in Education.

Demmert, W. G., \& Towner, J. C. (2003). A review of the research literature on the influences of culturally based education on the academic performance of Native American students. Paper presented to the Department of Education Washington, DC.

Fulford, G., Moore Daigle, J., Stevenson, B., Tolley, C., \& Wade, T. (2007). Sharing our success: Ten case studies in Aboriginal schooling. Kelowna, BC: Society for the Advancement in Excellence.

Fullan, M. (2003). Change forces with a vengeance. New York, NY: RoutledgeFalmer.

Fullan, M. (2004). Leadership and sustainability: System thinkers in action. Thousand Oaks, CA: Corwin Press.

Grissmer, D. \& Flanagan, A. (2006). Improving the achievement of Tennessee students: Analysis of the national assessment of educational progress. Santa Monica, CA: Rand Education.

Helin, C. (2008). Dealing with dependency: Out of poverty through self-reliance. Woodland Hills, CA: Ravencrest.

Kovach, M. (2009). Indigenous Methodologies-Characteristics, Conversations, and Contexts. Toronto: University of Toronto Press.

Kovach, M. (2010). Conversational method in Indigenous research. First Peoples Child \& Family Review. 5(1), 40-48.

Maguire, P. (2003). District practices and student achievement. Kelowna, BC: Society for the Advancement of Excellence in Education.

Richards, J. (2008). Explaining the Aboriginal-non-Aboriginal gap in student performance in BC schools. Paper presented at the Annual Meeting of the Canadian Economics Association, University of British Columbia, Vancouver, BC.

Richards, J. \& Scott, M. (2009). Aboriginal education: Strengthening the foundations. Ottawa: Canadian Policy Research Network: CPRN Research Report.

Smith, W. J., Bear, M., Corrigan, W. E., \& Quinn, K. (2008). Communication, accountability: Follow-up for school improvement. Paper prepared for Cree School Board Educational Review 2007-08, Quebec.

Yorkton Tribal Council (2009). Improving student learning: A study of the contribution of enhanced second- level services within the Yorkton Tribal Council in relation to the Saskatchewan PreK-12 educational system. Research publication prepared for the Saskatchewan Ministry of Education, Indian and Northern Affairs Canada, and the Saskatchewan Instructional Development and Research Unit. 